Article

\title{
Improving Animal Health on Organic Dairy Farms: Stakeholder Views on Policy Options
}

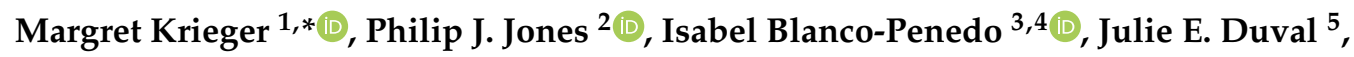 \\ Ulf Emanuelson ${ }^{4}$, Susanne Hoischen-Taubner ${ }^{1}$, Karin Sjöström ${ }^{4}$ and Albert Sundrum ${ }^{1}$ \\ 1 Department of Animal Nutrition and Animal Health, University of Kassel, 37213 Witzenhausen, Germany; \\ susanne.hoischen@uni-kassel.de (S.H.-T.); sundrum@uni-kassel.de (A.S.) \\ 2 School of Agriculture, Policy and Development, University of Reading, Reading RG6 6AR, UK; \\ p.j.jones@reading.ac.uk \\ 3 Animal Welfare Program, Institute of Agrifood Research and Technology_IRTA, 17121 Monells, Spain; \\ isabel.blanco.penedo@slu.se \\ 4 Department of Clinical Sciences, SLU, 75007 Uppsala, Sweden; ulf.emanuelson@slu.se (U.E.); \\ karin.sjostrom@slu.se (K.S.) \\ $5 \quad$ BIOEPAR, Oniris, INRA, 44307 Nantes, France; julie.duval@gmail.com \\ * Correspondence: margret.krieger@uni-kassel.de; Tel.: +49-561-804-1661
}

Received: 27 February 2020; Accepted: 8 April 2020; Published: 9 April 2020

check for updates

\begin{abstract}
Although ensuring good animal health is a stated aim of organic livestock farming and an important reason why consumers purchase organic products, the health states actually achieved are comparable to those in conventional farming. Unfortunately, there have been no studies to date that have assessed stakeholder views on different policy options for improving animal health on organic dairy farms. To address this deficit, stakeholder consultations were conducted in four European countries, involving 39 supply-chain stakeholders (farmers, advisors, veterinarians, inspectors, processors, and retailers). Stakeholders were encouraged to discuss different ways, including policy change, of improving organic health states. Acknowledging the need for further health improvements in organic dairy herds, stakeholders generally favoured establishing outcome-oriented animal health requirements as a way of achieving this. However, as a result of differing priorities for animal health improvement, there was disagreement on questions such as: who should be responsible for assessing animal health status on organic farms; and how to define and implement minimum health requirements. The results of the study suggest that future research must fully explore the opportunities and risks of different policy options and also suggest ways to overcome the divergence of stakeholders' interests in public debates.
\end{abstract}

Keywords: production diseases; dairy cows; organic farming; health requirements; outcome-oriented measures; stakeholder consultation; policy instruments

\section{Introduction}

Animal health is a public good that, in the absence of market rewards for producers, has to be guaranteed by policy [1]. According to Fraser [2], basic health and functioning (and especially freedom from disease and injury) is one of the three criteria of animal welfare, alongside natural living and affective states. Broom [3] deduces that an impairment of animal health always affects animal welfare. Therefore, disease, body damage, and reduced life expectancy are all measures of poor welfare [4]. In the European Union, the health and welfare of dairy cattle (with the exception of calves) is not regulated by species-specific legislation [5]. For other farmed species, such as pigs, calves, laying hens, and meat chickens, comprehensive regulatory instruments exist, in the form of EU Directives. 
These Directives regulate animal health and welfare solely through input-side requirements, such as space allowances in housing [6]. This situation persists despite the fact that the European Union Animal Welfare Strategy (2012-2015) promises to consider the development of a system of regulation based on the use of outcome-oriented indicators [7]. The potential benefits of using outcome-based indicators is recognised at the international level, for example by the World Organisation for Animal Health (OIE), which stated: “ ... animal welfare standards should be based on sound science. They should focus on the results achieved for the animal and they should always seek to maintain health as a basis of welfare." [8].

Organic livestock farming explicitly aims to achieve high levels of animal health and welfare [9]. Indeed, the belief that elevated levels of health and welfare are being routinely achieved is an important driver of the consumer purchase of organic livestock products [10,11]. The presumption of the routine achievement of good health and welfare status is also reflected in EU organic regulations. Regulation (EC) 834/2007, for example, requires that animal health and welfare be achieved by meeting animals' behavioural needs, providing adequate and appropriate housing, providing high quality feed, and implementing good husbandry practices [12]. Many private organic labels, e.g., Bioland (Germany), KRAV (Sweden), and Bio Cohérence (France), enforce standards above these EU minima [13]. However, these private organic labels are also limited to standard setting through the specification of resource- and management-based requirements. While improved levels of resource inputs and specified management obligations can provide animals with enhanced opportunities to perform natural behaviours (e.g., grazing on pasture and comfortable resting in bedded areas) and improve affective states (e.g., by reducing painful procedures and providing enriched environments), merely providing more and better inputs does not guarantee improved physiological health. It is unsurprising, then, that animal health has been identified as the primary welfare risk in organic livestock systems [14]. This state of affairs presents an unmitigated risk to the welfare-friendly image of organic agriculture; a risk that increases with the growth of the sector [15], and the increasing dominance of organic farmers motivated by economic rather than ideological considerations [16].

Rather than solely relying on standard-setting and the monitoring of resource inputs, the organic sector, as a means to greater achievement of these public goods, could also enforce outcome-oriented standards and monitor compliance using indicators that directly measure health and welfare states. The enhanced animal health and welfare so achieved would safeguard consumer trust in the organic concept. A particular challenge for legislators, in contributing to such developments, is that the concept of organic farming has been developed by market actors, including producers, and sustained by consumers, through specialist markets [17]. Some argue that, for this reason, government is not at liberty to unilaterally modify the legal requirements of organic livestock production but rather would have to work with, or through, relevant private stakeholders in order to preserve the integrity of the concept [18]. Based on this understanding, this study, via a consultation with supply-chain stakeholders, seeks to identify the most prospective policy options for securing animal health improvements on organic dairy farms, as one critical precondition for good animal welfare. To achieve this aim the study addresses two questions:

1. What policy and market conditions would be required to (a) ensure the routine measurement of the current health status of organic dairy cattle, (b) set targets for outcome-oriented animal health indicators, and (c) ensure remedial actions to deal with performance failures?

2. What policy options would lead farmers to achieve more aspirational animal health statuses?

\section{Materials and Methods}

\subsection{Terminology}

In this paper, the term legislation refers to state-based regulatory systems, while the term standard(s) refers to all other regulatory systems, e.g., private certification and assurance schemes, policies, programmes, voluntary codes of practice, etc. The terms regulation and requirement refer to both 
legislation and standards. The term resource-based measures relates to the physical environment and resources that are available to an animal, such as bedding material, space allocation, etc., whereas the term management-based measures relates to farm management practices, such as the feeding regime, etc. [19]. The term outcome-oriented is used in place of animal-based to describe metrics of animal health and welfare, such as disease prevalence, lameness score, etc. The word measure, in this paper, is used to mean a form of evaluation rather than an intervention that addresses a certain problem.

\subsection{Data Collection}

This study employed an across-method triangulation, i.e., it combined qualitative and quantitative methods of observational research. Drawing on multi-stakeholder consultation approaches, as described by Häring et al. [20], a variant of the focus group technique was used. Morgan et al. [21] define focus groups as a research technique that collects (qualitative) data through group discussion on a topic determined by a researcher. The focus groups in this study fulfilled all three essential aspects of this definition by (i) their primary purpose being research, (ii) allowing interactive discussions between participants and (iii) employing an interviewer (facilitator) who directed the discussion according to the research goals. Complementarily to the focus groups, and upon their conclusion, a quantitative survey was conducted (with the same stakeholders), collecting data to ensure completeness of coverage and to identify any collective similarities and differences.

These stakeholder consultations were undertaken as part of the work programme of the EU-funded research project IMPRO (www.impro-dairy.eu). Four case study countries were chosen, i.e., France, Germany, Spain, and Sweden, specifically to capture some of the important variation in the organic dairy food chains found in Europe (see also [22]). Häring et al. [20] have argued that multi-stakeholder consultations-if they are not properly planned, structured, and managed, and if there is an inadequate common vision - can fail to achieve positive results. To reduce such risks, a common roadmap was developed for all stakeholder consultations, defining goals and providing procedural structure such as guiding questions for the discussions (available from the first author upon request). To minimize researcher bias, external chairpersons acted as the facilitators.

A purposive, convenience sampling approach was used to obtain a sample of stakeholders from seven stakeholder groups, i.e., organic farmers, farm advisors, veterinarians, inspectors, milk processors, retailers, and academic researchers. The aim of the sampling was to include two persons from each of these groups in each of the case study focus groups, thereby capturing the greatest range of perspectives on the topic of improving animal health on organic dairy farms. The sampling was purposive, to ensure the inclusion of representatives of each of the key stakeholder groups, and it was convenient in that individuals in closer proximity to the researchers were selected over those that were more remote. Due to the constraints of availability and unforeseen circumstances, the actual sample was smaller than originally planned. Consequently, four consultation workshops, with 9-11 participants each, were held between Jan and Feb 2015, one in each of the study countries (Table 1). These were also attended by at least one of the authors (not counted).

Each workshop began with an introduction, which included an explanation of the workshop aims and agenda, a commitment to confidentiality (i.e., an agreement that no participant would be individually identifiable in any reporting), and a short round of personal introductions. This was followed by a short presentation emphasising animal health as a key aim of organic animal husbandry and pointing out the lack of outcome-oriented animal health requirements in current legislation and private standards. Group discussion was facilitated through a pre-defined set of questions, for example, "What indicators would you use to determine whether a farm has reached the goal of good animal health?". Summaries of answers were collected on moderation cards and arranged on pin boards (with picture protocols taken). When all ideas related to the first set of guiding questions were exchanged and nothing new was being added to the discussion, the facilitator wrapped up and moved on to the next agenda item. This involved participants being presented with data on the health status of organic dairy animals in each study country (see [23]) and asked for their reaction to these data, for example 
by asking "Did you expect these results and did you find them satisfactory?". Further questions were used to guide the discussion of this issue and to encourage participants to express their ideas and make suggestions in relation to policy options for further improving animal health on organic dairy farms. The collection of qualitative data ended after the second round of group discussions, and following this came the quantitative survey. In the survey questionnaire, participants were asked to indicate their level of agreement with statements representing different types of societal response to the observed animal health trends, using a ranking scale from 1 ("I do not agree at all") to 5 ("I fully agree"). Responses were collected anonymously and could be given either on paper or by use of a "clicker". After data collection, the aggregate answers were presented back to stakeholders using visual displays. Group discussion of these answers was then facilitated. Each workshop ended with a wrap-up session, where facilitators summarised the main conclusions and identified any unresolved questions, collected feedback on content and moderation, and thanked all participants for their input.

Table 1. Numbers of stakeholders, by type, attending the consultations in the four study countries.

\begin{tabular}{ccccc}
\hline & France & Germany & Spain & Sweden \\
\hline Farmers & 1 & $1^{\mathrm{a}}$ & $2^{\mathrm{a}}$ & $2^{\mathrm{a}}$ \\
Advisors & 2 & $5^{\mathrm{b}}$ & $1^{\mathrm{b}}$ & $3^{\mathrm{b}}$ \\
Veterinarians & 2 & $1^{\mathrm{b}}$ & $2^{\mathrm{b}}$ & $3^{\mathrm{b}}$ \\
Inspectors & - & 1 & - & 1 \\
Processors & - & $1^{\mathrm{a}}$ & - & $2^{\mathrm{a}}$ \\
Retailers $_{\text {Researchers }}$ & - & - & $2^{\mathrm{a}}$ & 1 \\
Others $^{1}$ & 5 & 1 & 5 & - \\
\hline Total $^{2}$ & - & 1 & 2 & - \\
\hline
\end{tabular}

\footnotetext{
${ }^{1}$ Germany: one practical foot trimmer; Spain: two technicians from the Spanish Milk Recording Scheme; ${ }^{2}$ Total does not equal the sum of the rows, because some stakeholders participated in dual roles (marked by the same letter, a or b).
}

The workshops ranged from 3 to 5 hours in duration. Audio recordings were made of the discussions in Germany and Spain, but in all countries, picture protocols and contemporaneous researcher notes were taken by designated note-takers. Notes were meant to be comprehensive and accurately reflect the content of the discussion.

\subsection{Data Editing and Analysis}

All hand-written notes were cleaned, completed, and translated into English by the respective note-takers, and sent to the first author, together with the above-named recordings and the survey results. Thematic analysis was performed on the qualitative data using a deductive approach, i.e., the identification of preconceived themes based on theory or existing knowledge. Verbatim text extracts providing interesting points of view or supporting arguments were organised in a separate protocol according to the pre-defined themes. If possible, responses to focus group questions were linked to the associated survey questions. The quantitative survey data were entered into Excel 2016 (Microsoft, Redmond, WA, USA) and analysed using the open-access analytics package R [24]. Non-parametric statistics (Kruskal-Wallis rank sum test, Wilcoxon-Mann-Whitney rank sum test) were used to assess differences between countries.

\subsection{Ethical Approval}

All data collection in the four stakeholder case studies was undertaken in accordance with the 1964 Helsinki declaration and its later amendments or comparable ethical standards. Before the studies, the institutional and/or national research committees were given detailed information on the project aims and methods. As the study was determined to be low risk for all participants, it did not require further ethical approval. Informed consent was obtained from all individual participants prior to the 
study. Participants were informed of the study's low risk status and given confidentiality undertakings, i.e., that no participant would be individually identifiable in any public presentations of the findings.

\section{Results and Discussion}

Most stakeholders were unsurprised by the data on the current levels of production diseases in organic dairy farms-something the majority also declared to be unsatisfactory and in need of improvement, particularly with regard to the worst-performing farms. Such views are likely to have been motivated both by a concern for the intrinsic welfare of these animals and a belief that these under-performing farms potentially threatened the "high welfare" image of the organic label [25]. Figure 1 shows that $86.5 \%$ of the respondents disagreed (scoring 2 or lower) with the statement "There is no need for action" (statement 1 ) and Figure 2 shows that $80.6 \%$ agreed (scoring 4 or higher) that organic farms failing to meet certain the minimum requirements for animal health should be obliged to take steps to improve (statement 3). Stakeholders regarded both the measurement of health status using outcome-oriented measures and the definition of minimum acceptable levels of performance using these measures as essential steps in achieving good animal health. These findings accord with the conclusions of Sundrum [26] and Darnhofer et al. [27], who argue that existing input-oriented production guidelines alone are insufficient to ensure the fulfilment of the key organic "principle of health". According to these authors, outcome-based indicators, combined with indicator targets describing desired outcomes, are required to ensure that organic farmers do not focus exclusively on implementing the minimum requirements necessary for certification.

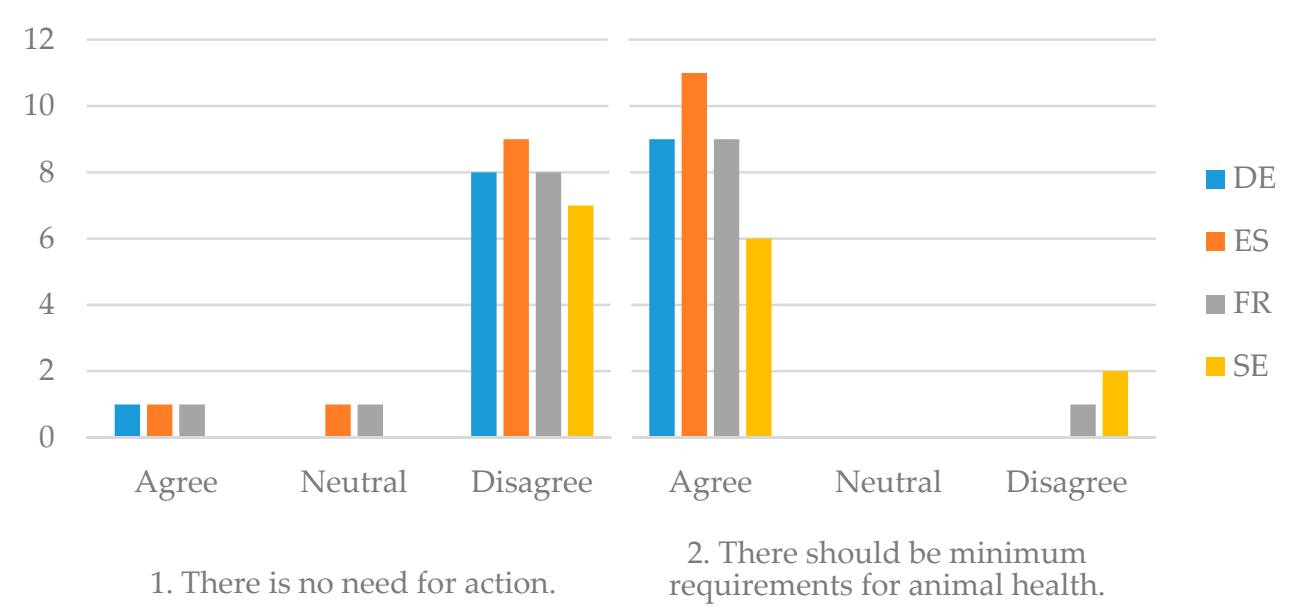

Figure 1. Stakeholder votes on statements 1 and 2 presented during consultations in Germany (DE), Spain (ES), France (FR), and Sweden (SE).

\subsection{Measuring Current Health Status}

The effective measurement of animal health status requires indicators that are both reliable and easy to measure. Three sources of such indicators were identified by stakeholders: (a) information already available in routinely collected databases, e.g., somatic cell counts in milk recording data, (b) information obtainable from the farmer by self-reporting, e.g., treatment records, and c) information that would need to be collected through farm inspections, e.g., lameness scores. These indicators differ in terms of their validity, reliability, and feasibility of collection. Most stakeholders regarded indicators available in extant databases as the most reliable and trustworthy. However, the limited availability of such data in some countries represents a major constraint to the EU-wide roll-out of health requirements based on the use of these indicators. To illustrate, only in Sweden are all commercially and publicly collected herd data related to performance and animal health combined into one central register, i.e., the National Cattle Database. In the other study countries, there is considerable heterogeneity in 
the data types and sources, and this heterogeneity will most certainly also be mirrored across the rest of the EU.

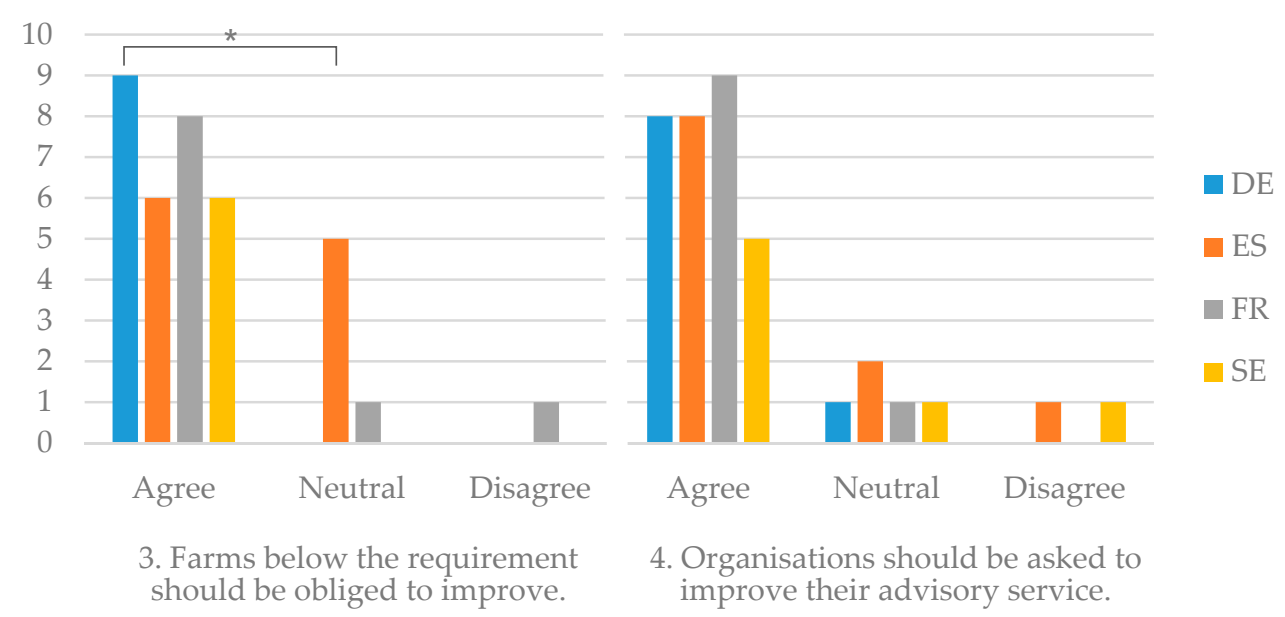

Figure 2. Stakeholder votes on statements 3 and 4 presented during consultations in Germany (DE), Spain (ES), France (FR), and Sweden (SE). Asterisks $\left({ }^{*} p<0.05\right)$ indicate statistically significant differences between groups.

Even where particular types of useful data are collected, this may not happen on all farms. For example, not all organic dairy farms participate in national or commercial milk recording schemes. Data structures will also vary between datasets and countries, and data may not be freely available to use for all actors with an interest in animal health, because of ownership constraints. To overcome these limitations, existing datasets must be supplemented with data collected directly from the farmer, for example, from foot trimming protocols and treatment records. The least feasible source of health data would be direct on-farm observations by trained assessors, for example, through on-site visits to record lameness scores. The use of such supplementary sources, some stakeholders argued, should only occur when absolutely necessary to fill in key data gaps. With continued market failure, there may be a need for regulatory action by government to ensure both the collection of, and access to, harmonised and relevant data.

Also lacking, from the perspective of some stakeholders, is a standardised way of using these metrics to express either regulatory minima or societal aspirations for health standards such that farmers, or their advisors, can use them (i.e., for benchmarking purposes) on their own farms.

\subsection{Minimum Health Status Requirements}

Unsurprisingly, there was a high level of agreement in support of introducing minimum requirements with regard to health outcomes, i.e., 92.1\% agreed with the statement (mean rank 4.3) that "There should be minimum requirements for animal health" (Figure 1, statement 2). However, there was disagreement over whether there should be legal provisions to enforce these requirements, or whether the requirements should be applied and monitored by private sector organisations. Swedish and German stakeholders generally favoured the former approach, while French and Spanish stakeholders supported the latter.

Miele and Lever [28] observed similar differences in attitude to government intervention in organic animal welfare management between France and Sweden, attributing these differences to underlying "national cultures", where Scandinavian countries are characterised by a welfare state model, which posits that the majority think that animals are being treated well because of the imposition of strict governmental regulations. In contrast, the terroir model found in France posits that animal welfare is mainly the result of producer-led schemes, within an encompassing concept of regionally-based taste and quality distinctives. 
However, stakeholders in all countries were in agreement that monitoring regimes involving minimum requirements should be established within certification schemes, based on outcome-oriented health requirements, so that the "rotten apples" could be identified. As a German participant put it: "Not every farmer has to reach the same level but there is a lower limit."

While respondents did not generally agree that science, or rather scientists, needed to be responsible for defining outcome-oriented reference values for animal health, there was a majority view $(60 \%$ agreed, mean rank 3.6) that scientific findings and (scientific) expert opinions should feed into such decisions (Figure 3, statement 5a).

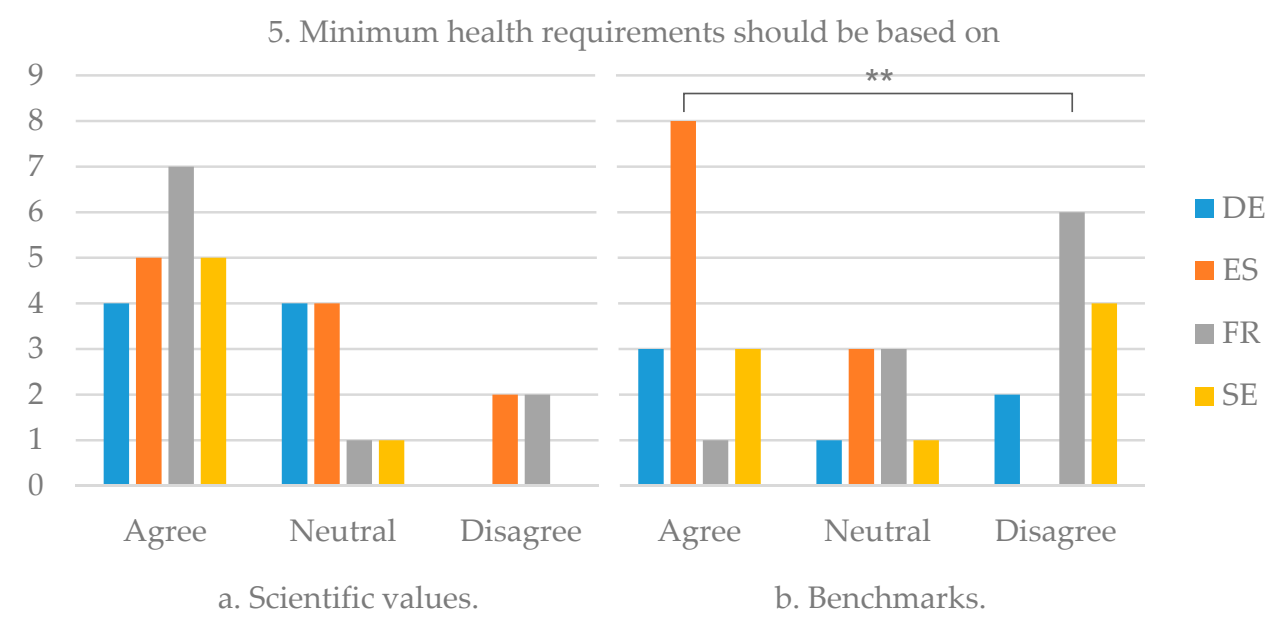

Figure 3. Stakeholder votes on statements $5 \mathrm{a}$ and $5 \mathrm{~b}$ presented during consultations in Germany (DE), Spain (ES), France (FR), and Sweden (SE). Asterisks $\left.{ }^{* *} p<0.01\right)$ indicate statistically significant differences between groups.

Such an approach has already been used in the development of indicators being used to address major welfare issues in conventional dairy farming in Germany [29,30]. There was concern among stakeholders that any new outcome-based minimum animal health requirements should not be expressed as absolute threshold values, as these could come to be seen as normative targets, i.e., farmers might aim for these targets and not seek to exceed them. An alternative way of setting outcome-oriented animal health targets would be via benchmarking [31,32], where the performance of a sub-group of the population serves as a reference for evaluating the individual. This approach is the basis, for example, of the Swedish "Animal Welfare Signals" [33]. An advantage of benchmarks is that they take into account the present situation and meet the population of farms where they stand, while signalling what others have been able to achieve under similar conditions, thereby affirming that higher standards are attainable. Because benchmarks are dynamic, they change whenever group performance changes, i.e., their aspirational goals continually evolve and cannot be overtaken by events, and so always retain their ability to drive change. As a way of motivating farmers to emulate the standards of better performing farms, March et al. [34] suggested an incentive scheme where subsidies are paid only to the top quartile of farms to reflect their additional efforts to improve welfare indicators.

The main risk with the benchmarking approach is perhaps that when the whole population is performing poorly, in absolute terms, the top quartile could still be interpreted as providing good animal health, thereby setting low targets for the rest. Also problematic would be an exceptionally high-performing top quartile, implying the need for big improvements from lagging farms, where they may already be meeting societally acceptable standards. Lagging farmers may also be intimidated by the magnitude of the improvements they would have to make to match the standards of the top performers and so think such standards unobtainable on their farms. These risks could explain why stakeholders were unsure about the use of benchmarks in this way (Figure 3, statement $5 b$ ), with only 
$42.9 \%$ (mean rank 3.1) advocating their use. Spanish participants were more in favour of minimum requirements being based on benchmarks than participants in France $(p=0.0012)$.

The setting of dynamic standards, derived from population sampling, would require large scale and frequent surveys to achieve credibility, perhaps suggesting an EU-level co-ordination of data collection and processing.

\subsection{Legislation and Market Differentiation}

There was no unanimity on the question of who should be responsible for measuring animal health and defining minimum health requirements. The position of the Spanish stakeholders was perhaps the most coherent, arguing that responsibility for health standards should be left to the market, while government should be limited to ensuring compliance with EU resource-based requirements, for the simple reason that:

"The organic label does not guarantee the quality of the product, only that it is produced organically."

Although the concept of animal welfare is much broader than the concept of animal health, two alternative policy mechanisms, i.e., state influence (government regulation) and market influence (initiatives of the market to differentiate animal products), apply equally to both [35]. Stakeholder attitudes to market influence were revealed in their agreement with the statement: "For organic farms with good animal health there should be a premium segment" (Figure 4, statement 6b). Fifty percent (mean rank 3.3) agreed, with only 25\% disagreeing with this statement. However, within the agreement group, there was considerable critical debate over possible dangers, as the following quotes illustrate:

"What would 'premium organic' say about 'ordinary organic'? There is a risk of watering down the brand." (Swedish stakeholder);

"Improving the already 'good' image of organic farms will only confuse the consumer, since it presupposes that there will be 'less good' organic farms which is inconsistent with the image that the consumer has in mind." (Spanish stakeholder).

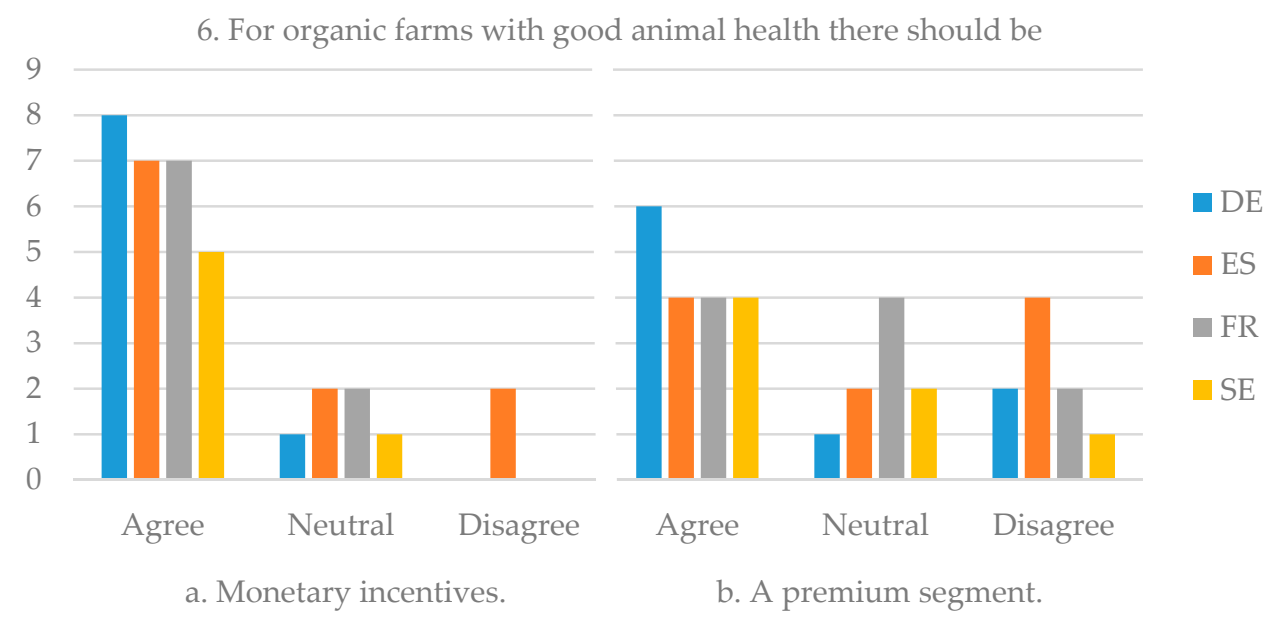

Figure 4. Stakeholder votes on statements $6 \mathrm{a}$ and $6 \mathrm{~b}$ presented during consultations in Germany (DE), Spain (ES), France (FR), and Sweden (SE).

This identification of the risk of consumer backlash associated with asking consumers to pay more for "improved" animal health when they already expect the delivery of good animal health and welfare when buying "normal" organic products replicates the findings of previous studies [36,37].

Each of the two putative policy mechanisms for setting health outcome standards, i.e., government legislation and market strategies, have their own advantages and drawbacks. Legislation targets the worst performers by delivering industry-wide and relatively uniform improvements in minimum 
production standards, although considerable variation above that minimum would be possible (see below). Market strategies (private standards) are constrained by the need to both appeal to consumers (i.e., other credence values may need to be considered) and remain economically viable. Market strategies may also only impact certain segments within the population of producers, i.e., those that are commercially engaged with the certifier. If the market defines animal health and distinguishes health standards using product labels, consumers are effectively asked to act upon their ethical or political preferences through their purchases. To do so, consumers must understand the added value behind the standards [38]. However, limited knowledge can result in an inability to make informed choices, as was shown by Żakowska-Biemans and Tekień [39], who found that consumers in Poland preferred free-range eggs over organic eggs because they could better relate to the concept of "free range" than of "organic". From the retailers' perspective, market strategies are quite demanding, requiring specific devices (labels, standards, and assurance schemes) and costly mechanisms of market creation (communication and advertising campaigns) and maintenance. A proliferation of new regulations, i.e., competing public and private labels and standards, would lead to confusion for both producers and consumers. Such proliferation would also create greater diversity in pricing and could increase the risk of fraud [40]. Furthermore, conflicting interests among actors in the supply chain can hamper any market-driven differentiation aimed at driving better animal health. Bueren et al. [41] labels such specialisation and fragmentation within the Dutch chicken meat supply chain "organised irresponsibility", leading to a blindness towards health and welfare issues and institutional inertia.

There are also downsides to determining animal health requirements through government legislation, i.e., consumers may assume that government controls are all sufficient and not take responsibility for encouraging ethical production via their purchases. This may lead to the situation found in Sweden where, due to government health and welfare regulations, market actors cannot find any competitive advantage in introducing private "higher welfare" labels [28]. Organic regimes combine elements of both market and legislative approaches, i.e., legislation underpins the production processes, but this only applies where farms have voluntarily joined the organic scheme, thereby leading to market differentiation. Stakeholders in this study generally felt that as consumers already expect that the delivery of these public goods is inherent in organic products, it may be better to ensure that the brand lives up to these expectations through the implementation of private or market control mechanisms, rather than gamble with public trust by trying to establish an organic premium label.

While market strategies have their downsides, they also offer some advantages. Private standards, for example, can be a substitute for legislation where this is either missing or inadequate to meet consumer demand for product differentiation [42]. For example, UK and Dutch retailers, responding to media and NGO pressure to act on behalf of animal welfare, required their suppliers to adopt private assurance schemes or instituted their own standards, which surpassed the EU regulatory minima [28]. Additionally, in Germany and France, an increasing engagement of private actors can be observed with respect to farm animal welfare, even while government actors are exercising restraint [43]. While market supplementation strategies are generally confined to only a small share of production, they can have a more extensive impact if they become the industry standard, as occurred, for example, with Assured Food Standards in the UK [28]. Operating at this level, private labelling may increase awareness and provide new opportunities by affecting how animal welfare is defined and interpreted in the marketplace. Perhaps this explains why half of the stakeholders in this study favoured the establishment of an extra "health" label on top of "basic organic". Across Europe, only a minority of consumers $(12 \%)$ believes that farm animal welfare should be left to market actors. However, $43 \%$ believe that farm animal welfare should be handled jointly by businesses and government [44].

Because of the differences between these two approaches, underlying values and outcomes may be highly variable depending on the economic actors controlling the mechanisms and their goals $[37,45]$. These differences may discourage some farmers from making investment decisions directed at improvements in animal health, until the uncertainty over which approaches will be followed is ended. 
Some German stakeholders, including those involved with certification schemes, expressed the opinion that animal health assurance is the duty of private organic certifiers and can be used as a means to raise their profiles. Some stakeholders saw benefits in all organic farms being assessed on the basis of animal health status, including those who were not members of an organic association (approximately $50 \%$ of organic farms in Germany). This would, arguably, protect the organic concept (which is expected to deliver products from healthy animals) and also oblige uncertified farms to use advisory services (and possibly contemplate certification scheme membership). Echoing Weary and Keyserlingk [46], a German veterinarian suggested that farms might perform their own quality assurance assessments (first party audits), with the self-recorded data inspected by an official agency. First-party audits can already be found operating in Sweden, where organic farmers must be able to show, and are therefore obliged to record, key performance indicators for animal health and welfare [47].

\subsection{Policy Instruments}

Stolze and Lampkin [17], identify three types of policy instrument that drive organic farming practice: legal instruments (regulation) based on the authority and power of the state; financial instruments (economic incentives or disincentives) based on the offer of financial support or the levying of taxes or duties; and communicative instruments that involve some kind of interaction between the regulated and the regulator. By way of an alternative classification, Ingenbleek et al. [48] differentiate between government-based, market-based, and farmer-based policy instruments. These two typologies are not mutually exclusive, in the sense that one can be nested in the other. However, as it would overcomplicate the discussion to attempt to use both simultaneously, the typology proposed by Stolze and Lampkin [17] is used below as a framework for understanding stakeholders' views on a range of different policy instruments, in terms of their likely efficacy, for driving future improvements in the health state of organic livestock.

\subsubsection{Legal Instruments: Disciplinary Sanctions}

A majority of stakeholders were sympathetic to the notion of introducing minimum requirements for animal health plus the use of disciplinary sanctions for poor performance (see Figure 5). These sanctions included admonishment, with 78.9\% agreement (mean rank 4.2); and in extreme cases, exclusion, with $83.3 \%$ agreement (mean rank 4.3). Both of these types of disciplinary sanction are currently being employed by certifiers, although, obviously, not in response to breaches of outcome-oriented animal health requirements.

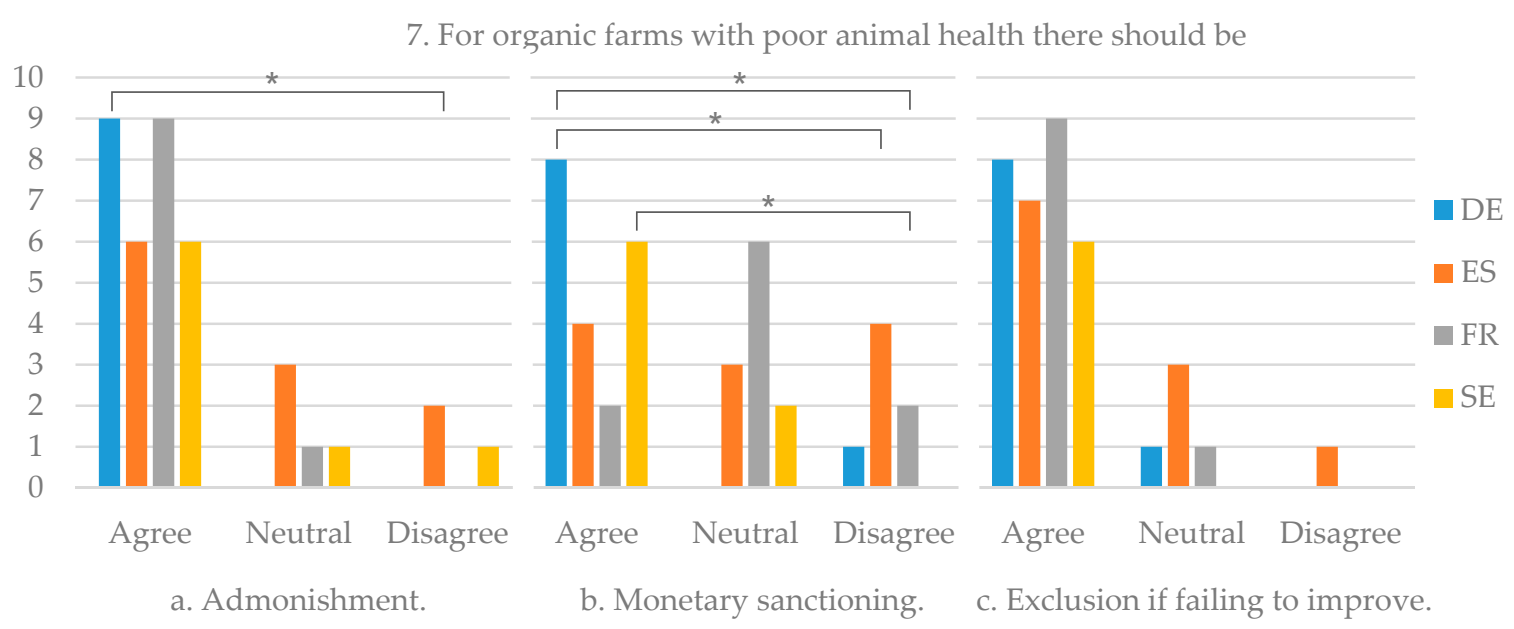

Figure 5. Stakeholder votes on statements 7a to 7c presented during consultations in Germany (DE), Spain (ES), France (FR), and Sweden (SE). Asterisks $\left({ }^{*} p<0.05\right)$ indicate statistically significant differences between groups. 
The existence of admonishment, as a disciplinary sanction for failure to reach certain standards of animal health, requires that animal health outcomes are regularly monitored and that failing farms are informed of their unacceptable status and asked to improve. Admonishment can therefore be viewed largely as an information service, albeit coupled with the threat of sanctions. By contrast, exclusion from the certification scheme is an action that has immediate and serious consequences. Farms that are excluded not only lose organic subsidies and price premiums, but potentially face reputational damage. The existence of the exclusion option, and public awareness of it, acts to motivate farmers to comply with stated requirements and safeguards the public perception that organic farms achieve certain minimum standards and that compliance is policed.

\subsubsection{Financial Instruments: Monetary Sanctions and Incentives}

Three quarters $(77.1 \%$, mean rank 4.1$)$ of stakeholders agreed with the notion of introducing financial incentives for the achievement of aspirational animal health states (Figure 4, statement 6a). Monetary sanctions (disincentives) for farms realising poor animal health states (Figure 5 , statement $5 \mathrm{~b}$ ) had much lower acceptance, at $52.6 \%$. These results clearly indicate a general preference for incentives over sanctions, or in the words of a Spanish participant:

"The improvement of health in organic farming should be primarily by positive reinforcement (incentives) and not by sanctions."

Underlying this presumption against sanctions might be a recognition that the market already partly sanctions poor animal health, i.e., on the production side, through high failure costs [49]. In light of this, sanctions would be seen as making a bad situation worse, by eroding the very financial resources needed for investment in health improvement interventions. In the words of a Spanish participant:

"Sanctions are not the way to go. Poor management has a negative effect on animal health and farm profitability anyway. Thus, farms would be doubly punished."

Although disease failure costs have been shown to be considerable in organic dairy farms [49], the awareness of this is not always sufficient to incentivise farmers to act. The problem is largely one of perception i.e., the economic losses resulting from production diseases are often not visible, while the costs of health improvement interventions (which can be considerable) are highly visible. Compounding this problem is the fact that, in given contexts, not all recommended control actions, even highly effective ones, will be cost effective [50]. To illustrate, Hogeveen et al. [51] estimated that of 18 actions identified as having the potential to control mastitis in a dairy herd, only six had positive cost-benefit ratios. In acknowledgement of such evidence, stakeholders noted that some animal health improvements may require the input of resources at a level that is greater than can be covered by the organic subsidies and premium prices, i.e., because they have significantly negative cost-benefit ratios. With the cost of health improvement interventions in view, one Spanish stakeholder stated:

"There should be concrete financial aid [from government] to improve animal health."

Spanish and German stakeholders differed significantly in terms of their agreement with the general obligation to improve for farms failing to meet a certain animal health requirement (Figure 2, statement $3, p=0.026$ ) and with the prospect of admonishment for poorly performing farms (Figure 5, statement $7 \mathrm{a}, p=0.0275)$. More country-based differences were found in the level of agreement with the use of financial sanctions, with substantially more agreement among the German and Swedish stakeholders than the Spanish and French (Figure 5, statement $7 \mathrm{~b}, p$-values $<0.05$ ). This is likely to be due to the cultural differences mentioned earlier, where Germany and Sweden have a long history of national animal welfare regulations with associated sanctions, in contrast to Spain, whose animal welfare legislation mainly exists because of demands from the European Union [45]. 


\subsubsection{Communicative Instruments: Advisory Services}

The great majority $(91.1 \%$, mean rank 4.0$)$ of stakeholders agreed that "Organisations should be asked to improve their advisory service" (Figure 2, statement 4). However, within this apparent unanimity, a number of different positions exist, such as this one expressed by a German stakeholder:

"Animal health is not achieved through inspection itself but through advisory and education. Having a common aim and creating awareness will lead to development and thus to improvement."

This position holds that advisory services and education are necessary additions to legal regulations, i.e., minimum requirements define the aim, while the achievement of the aim is realised through (and requires) stakeholder interaction and social learning. A somewhat different perspective is articulated by the following statement by a Spanish stakeholder:

"I am not a supporter of awards nor punishments for farms, but help is okay."

This position holds that (enhanced) advisory services alone would be sufficient to achieve aspirational animal health improvements, i.e., without regulation and sanction. Unfortunately, the evidence does not support this hypothesis [52], even in countries where advisory provision is good. However, supporters of this position may argue that this communicative instrument would indeed be effective if sufficient efforts were made to enhance the quality and availability of the advisory offering. A number of studies have indeed identified substantive weaknesses in current advisory provisions, including Duval et al. [53], who noted a loss of veterinary support for organic farmers in the west of France, resulting from a lack of mutual understanding and dialogue between farmers and advisors. Veterinarians, the authors argue, must be more willing to understand individual farmers' objectives, values, and priorities and to tailor their advice to the farm-specific situation. Eshuis and Stuiver [54] argue that farmers and their advisors need to respect each others' knowledge, create good relationships, exchange experiences, and jointly generate new knowledge as part of contextual, social learning processes.

Some German stakeholders proposed a third position, i.e., taking a more regulatory line, where there is a legal obligation for farmers to seek advisory support if they fail to meet required animal health states. This combination of legal and communicative instruments mimics the approach already being taken in Sweden, where the organic association KRAV requires farmers who are identified as having poor animal health status, using the "Animal Welfare Signals" (Signaler Djurvälfärd), to take additional actions, with the support of a local variant of the dairy management training organisation CowSignals ${ }^{\circledR}$ [55]. Such an approach emphasises the important role of communication in motivating farmers to look after the welfare of the animals in their care [56].

\subsection{Policy Implications}

Any choice of policy instruments to serve a specific purpose should always be based on the evaluation criteria of effectiveness and feasibility [48], i.e., it must be both practicable and achieve the specific objectives that are desired. In the context of animal welfare, McInerney [57] suggests that the desired level of welfare will itself determine the choice of policy instrument, i.e., regulation and its enforcement is generally suitable for the achievement of lower animal welfare targets, while market-based actions, sometimes in combination with farmer-based actions, are more suitable for the achievement of higher animal welfare targets. Accepting this as true, in order to achieve more aspirational health and welfare targets, it makes sense to deploy both approaches. Foundational animal health outcomes would be delivered through universal regulation, while the more aspirational levels of animal health associated with organic production could then be enforced or encouraged specifically through market-based instruments. In the consultations, it became obvious that different stakeholders in the organic dairy supply-chain had different priorities and saw different opportunities for the choice of policy instruments. This may be due to their use of different evaluation criteria according to their 
interests [48]. The number of stakeholders in each group was, unfortunately, too low in this study to permit the statistical investigation of the significance of these differences.

\subsection{General Methodological Considerations}

The aim of this study was to explore, with relevant multi-national supply-chain stakeholders, the suitability and desirability of a range of policy options for improving animal health in organic dairy systems. Naturally, the stakeholder consultations were constrained in terms of size and time, and therefore cannot be expected to yield a complete picture of what is a very complex and contested area. Participation in the consultation was on the basis of both invitation and availability, and so there may be some self-selection bias at work, meaning that the views of the groups may not be fully representative of all views within the organic sector. In all countries, the aim was to include two persons of each stakeholder group. However, as shown in Table 1, the actual selection of stakeholders deviated from that aim. Advisors, veterinarians, and farmers were present in all of the four consultations, whereas scientists, inspectors, dairies, food retailers, and farmer organisations were only present in some countries. Some stakeholders also participated in dual roles, e.g., advisors belonging to farmers' associations. While these limitations suggest that the outcomes of the discussions should only be taken as providing a flavour of the variability in viewpoints across the different stakeholder groups and across countries, it is hoped that the consultations have captured the major extant viewpoints. The actual combinations of stakeholders in each consultation may have affected the type of responses in both the qualitative and quantitative surveys. Therefore, the differences found between countries may be influenced by the mix of stakeholder types in each country. For example, advisors and veterinarians dominated the discussions in Germany and France, whereas researchers were the dominant participants in France and Spain. As the quantitative survey was anonymous, there was no possibility of further investigating this potential source of bias. Future research should focus on better understanding the potential differences between different types of stakeholder.

A triangulation method was used to create a better understanding of the data and to strengthen the outcome of the study, i.e., qualitative data was collected to gain in-depth knowledge on what is a complex subject, while the quantitative study assessed stakeholders' agreement with respect to different strategies. Using such a combination of methods can have distinct benefits as well as pose risks [58]. In this study, the focus group discussions at the workshops were deliberately scheduled before the survey, so as not to influence the discussion by presenting pre-defined statements. As a result, the qualitative data collected was able to complement and clarify the quantitative findings. Generally, transcripts of audio recordings more accurately reflected participants' views than contemporaneous researcher notes. As the type of recording (visual and audio), as well as the comprehensiveness of the researcher notes, differed between focus groups, there may have been some further country bias in the qualitative analysis. Having said that, it is worth remembering that the quantitative analysis was conducted to a good procedural standard in all countries.

\section{Conclusions}

The results of this study reinforce the view that the use of a multi-layered animal health assessment, using outcome-oriented metrics of production disease states, farms currently not meeting the organic target of good animal health can be successfully identified. However, while there may be broad agreement about the benefits of deploying outcome-oriented animal health requirements, there are divergent views between stakeholders and between countries on how to set such requirements, what level they should be set at, and how they should be implemented. Access to appropriate farm-based data and harmonised metrics are prerequisites for determining current animal health status. Future research should therefore focus on ways to improve the quality and availability of such data, increasing the choice of suitable outcome-oriented indicators that are available, and strategies for using this information most effectively. The opportunities and risks of different policy options to deliver animal health requirements must be explored in future research, and future debate must suggest ways 
to overcome the divergence of the interests of stakeholders so that agreement on policy choices can be reached. Only by this means will it be possible to achieve the common goal of ensuring the credibility of the organic sector regarding animal health and welfare.

Author Contributions: Conceptualization, M.K., I.B.-P., U.E., S.H.-T. and A.S.; methodology, M.K., I.B.-P., J.E.D., U.E., S.H.-T. and K.S.; validation, M.K., P.J.J., I.B.-P., J.E.D., U.E., S.H.-T. and K.S.; formal analysis, M.K.; investigation, M.K., I.B.-P., J.E.D., U.E., S.H.-T. and K.S.; resources, M.K., I.B.-P., J.E.D., U.E., S.H.-T. and K.S.; data curation, M.K.; writing —original draft preparation, M.K. and P.J.J.; writing-review and editing, M.K., P.J.J., I.B.-P., J.E.D., U.E., S.H.-T., K.S. and A.S.; visualization, M.K.; supervision, U.E. and A.S.; project administration, A.S.; funding acquisition, U.E., I.B.-P., S.H.-T. and A.S. All authors have read and agreed to the published version of the manuscript.

Funding: This research was funded by the European Union's Seventh Framework Programme, grant number 311824 .

Acknowledgments: The authors would like to thank all participating stakeholders for their input together with all those who assisted in organising and evaluating the consultations. We wish to thank the two anonymous reviewers for their efforts and for their valuable comments.

Conflicts of Interest: The authors declare no conflict of interest.

\section{References}

1. Eloit, M. The global public good concept: A means of promoting good veterinary governance. Rev. Off. Int. Epizoot. 2012, 31, 577-590. [CrossRef]

2. Fraser, D. Understanding animal welfare. Acta Vet. Scand. 2008, 50 (Suppl. 1), S1-S12. [CrossRef]

3. Broom, D.M. Behaviour and welfare in relation to pathology. Appl. Anim. Behav. Sci. 2006, 97, 73-83. [CrossRef]

4. Broom, D.M. Animal welfare defined in terms of attempts to cope with the environment. Acta Agric. Scand. Sect. A Anim. Sci. Suppl. 1996, 27, 22-28.

5. Nalon, E.; Stevenson, P. Protection of Dairy Cattle in the EU: State of Play and Directions for Policymaking from a Legal and Animal Advocacy Perspective. Animals 2019, 9, 1066. [CrossRef]

6. Stevenson, P. Review of Animal Welfare Legislation in the Beef, Pork, and Poultry Industries; FAO: Rome, Italy, 2014; Available online: http://www.fao.org/3/a-i4002e.pdf (accessed on 8 April 2020).

7. European Commission (EC). European Union Strategy for the Protection and Welfare of Animals 2012-2015; COM (2012), 6 final/2, EC. Brussels, Belgium, 2012. Available online: https://ec.europa.eu/food/sites/food/files/ animals/docs/aw_eu_strategy_19012012_en.pdf (accessed on 25 March 2020).

8. World Organisation for Animal Health (OIE). Animal Welfare at a Glance. Available online: www.oie.int/en/ animal-welfare/animal-welfare-at-a-glance/ (accessed on 29 May 2019).

9. International Federation of Organic Agriculture Movements (IFOAM). The IFOAM Norms for Organic Production and Processing; IFOAM-Organics International: Bonn, Germany, 2019; Available online: https: //www.ifoam.bio/sites/default/files/ifoam_norms_july_2014_edits_2019.pdf (accessed on 25 March 2020).

10. Harper, G.C.; Makatouni, A. Consumer perception of organic food production and farm animal welfare. Br. Food J. 2002, 104, 287-299. [CrossRef]

11. McEachern, M.G.; Willock, J. Producers and consumers of organic meat. Br. Food J. 2004, 106, 534-552. [CrossRef]

12. Council Regulation (EC) No 834/2007 of 28 June 2007 on Organic Production and Labelling of Organic Products and Repealing Regulation (EEC) No 2092/91; Official Journal of the European Union L 189/1; Luxembourg, 2007.

13. Arcuri, A. The Transformation of organic regulation: The ambiguous effects of publicization. Regul. Gov. 2015, 9, 144-159. [CrossRef]

14. Sutherland, M.A.; Webster, J.; Sutherland, I. Animal Health and Welfare Issues Facing Organic Production Systems. Animals 2013, 3, 1021-1035. [CrossRef]

15. EUROSTAT. Organic Farming Survey. Available online: http://appsso.eurostat.ec.europa.eu/nui/show.do? dataset=org_coptyp (accessed on 4 June 2019).

16. Best, H. Organic agriculture and the conventionalization hypothesis: A case study from West Germany. Agric. Hum. Values 2008, 25, 95-106. [CrossRef] 
17. Stolze, M.; Lampkin, N. Policy for organic farming: Rationale and concepts. Food Policy 2009, 34, $237-244$. [CrossRef]

18. Schmid, O.; Dabbert, S.; Eichert, C.; Gonzalvez, V.; Lampkin, N.; Michelsen, J.; Slabe, A.; Stokkers, R.; Stolze, M.; Stopes, C. (Eds.) Organic Action Plans. Development, Implementation and Evaluation; A Resource Manual for the Organic Food and Farming Sector; FiBL: Frick, Switzerland, 2008; ISBN 978-3-03736-022-4.

19. EFSA. Statement on the use of animal-based measures to assess the welfare of animals. EFSA J. 2012, 10, 344. [CrossRef]

20. Häring, A.M.; Vairo, D.; Dabbert, S.; Zanoli, R. Organic farming policy development in the EU: What can multi-stakeholder processes contribute? Food Policy 2009, 34, 265-272. [CrossRef]

21. Morgan, D.L. Focus Groups. Annu. Rev. Sociol. 1996, 22, 129-152. [CrossRef]

22. Van Soest, F.J.S.; Mourits, M.C.M.; Hogeveen, H. European organic dairy farmers' preference for animal health management within the farm management system. Animal 2015, 9, 1875-1883. [CrossRef] [PubMed]

23. Krieger, M.; Sjöström, K.; Blanco-Penedo, I.; Madouasse, A.; Duval, J.E.; Bareille, N.; Fourichon, C.; Sundrum, A.; Emanuelson, U. Prevalence of production disease related indicators in organic dairy herds in four European countries. Livest. Sci. 2017, 198, 104-108. [CrossRef]

24. R Core Team. R: A Language and Environment for Statistical Computing; R Foundation for Statistical Computing: Vienna, Austria, 2017; Available online: https://www.R-project.org/ (accessed on 4 June 2019).

25. Von Borell, E.; Sørensen, J.T. Organic livestock production in Europe: Aims, rules and trends with special emphasis on animal health and welfare. Livest. Prod. Sci. 2004, 90, 3-9. [CrossRef]

26. Sundrum, A. Organic Livestock Production. In Encyclopedia of Agriculture and Food Systems; van Alfen, N.K., Ed.; Academic Press: Oxford, UK, 2014; pp. 287-303. ISBN 978-0-08-093139-5.

27. Darnhofer, I.; Lindenthal, T.; Bartel-Kratochvil, R.; Zollitsch, W. Conventionalisation of organic farming practices: From structural criteria towards an assessment based on organic principles. A review. Agron. Sustain. Dev. 2010, 30, 67-81. [CrossRef]

28. Miele, M.; Lever, J. Improving animal welfare in Europe. In Sustainable Food Systems: Building a New Paradigm; Marsden, T., Morley, A., Eds.; Routledge: London, UK, 2014; pp. 143-165. ISBN 0415639557.

29. Brinkmann, J.; March, S. Tiergesundheit [Animal health]. In Faustzahlen für den Ökologischen Landbau [Reference Values for Organic Farming]; KTBL, Ed.: Darmstadt, Germany, 2015; pp. 472-477. ISBN 3945088054.

30. Brinkmann, J.; March, S.; Renziehausen, C.; Bergschmidt, A. Indicators for a result-oriented approach for animal welfare policies and organic farming. In Proceedings of the 6 th International Conference on the Assessment of Anim. Welfare at Farm and Group Level, WAFL 2014, Clermont-Ferrand, France, 3-5 September 2014; Mounier, L., Veissier, I., Eds.; Wageningen Academic Publishers: Wageningen, The Netherlands, 2014; p. 88.

31. Werner, C.; Löser, R.; Kempkens, K.; Sundrum, A. Leitlinien zur Sicherung der Tiergesundheit in der ökologischen Schweineerzeugung [Guidelines to secure animal health in organic pig production]. Landbauforschung Völkenrode Sonderheft 2008, 320, 99-108.

32. Sumner, C.L.; von Keyserlingk, M.A.G.; Weary, D.M. Perspectives of farmers and veterinarians concerning dairy cattle welfare. Anim. Front. 2018, 8, 8-13. [CrossRef]

33. Växa Sverige. Signaler Djurvälfärd. Available online: https://www.vxa.se/radgivning-och-kurser/analyseranulaget/analysera-djurhalsan/signaler-djurvalfard/ (accessed on 29 May 2019).

34. March, S.; Bergschmidt, A.; Renziehausen, C.; Brinkmann, J. Indicators for a Payment-by-Results Approach for Animal Welfare Measures and Organic Farming; Final Report; BÖLN Project, 11NA026, Thünen Institute: Braunschweig, Germany, 2017.

35. Ingenbleek, P.T.M.; Harvey, D.; Ilieski, V.; Immink, V.M.; de Roest, K.; Schmid, O. The European Market for Animal-Friendly Products in a Societal Context. Animals 2013, 3, 808-829. [CrossRef] [PubMed]

36. Von Meyer-Höfer, M.; Nitzko, S.; Spiller, A. Is there an expectation gap? Consumers' expectations towards organic. Br. Food J. 2015, 117, 1527-1546. [CrossRef]

37. Buller, H.; Roe, E. Commodifying animal welfare. Anim. Welf. 2012, 21, 131-135. [CrossRef]

38. Kjærnes, U.; Harvey, M.; Warde, A. Trust in Food. A Comparative and Institutional Analysis; Palgrave Macmillan: Basingstoke, UK, 2007; ISBN 9780230627611.

39. Żakowska-Biemans, S.; Tekień, A. Free Range, Organic? Polish Consumers Preferences Regarding Information on Farming System and Nutritional Enhancement of Eggs: A Discrete Choice Based Experiment. Sustainability 2017, 9, 1999. [CrossRef] 
40. Dabbert, S.; Lippert, C.; Schulz, T.; Zorn, A. CERTCOST-Economic analysis of certification systems for organic food and farming at EU level. In Cultivating the Future Based on Science, Proceedings of the Second Scientific Conference of the International Society of Organic Agriculture Research (ISOFAR), held at the 16th IFOAM Organic World Congress in Cooperation with the International Federation of Organic Agriculture Movements (IFOAM) and the Consorzio ModenaBio, Modena, Italy, 18-20 June 2008; Neuhoff, D., Halberg, T., Alföldi, N., Lockeretz, W., Thommen, A., Rasmussen, I.A., Hermansen, J., Vaarst, M., Lueck, L., Caporali, F., et al., Eds.; International Society of Organic Agriculture Research (ISOFAR), c/o IOL: Bonn, Germany; Research Institute of Organic Agriculture FiBL: Frick, Switzerland, 2008; pp. 390-393.

41. Van Bueren, E.M.; Lammerts van Bueren, E.T.; van der Zijpp, A.J. Understanding wicked problems and organized irresponsibility: Challenges for governing the sustainable intensification of chicken meat production. Curr. Opin. Environ. Sustain. 2014, 8, 1-14. [CrossRef]

42. Henson, S.; Reardon, T. Private agri-food standards: Implications for food policy and the agri-food system. Food Policy 2005, 30, 241-253. [CrossRef]

43. Vogeler, C.S. Market-Based Governance in Farm Animal Welfare-A Comparative Analysis of Public and Private Policies in Germany and France. Animals 2019, 9, 267. [CrossRef]

44. European Commission (EC). Special Eurobarometer 442: Attitudes of Europeans towards Animal Welfare. Available online: http://data.europa.eu/euodp/data/dataset/S2096_84_4_442_ENG (accessed on 31 March 2020).

45. Lundmark, F.; Berg, C.; Schmid, O.; Behdadi, D.; Röcklinsberg, H. Intentions and values in animal welfare legislation and standards. J. Agric. Environ. Ethics 2014, 27, 991-1017. [CrossRef]

46. Weary, D.M.; von Keyserlingk, M.A.G. Public concerns about dairy-cow welfare: How should the industry respond? Anim. Prod. Sci. 2017, 57, 1201. [CrossRef]

47. KRAV. Standards for KRAV-Certified Production, 2019-20 ed.; The KRAV Association: Uppsala, Sweden, 2018.

48. Ingenbleek, P.T.M.; Immink, V.M.; Spoolder, H.A.M.; Bokma, M.H.; Keeling, L.J. EU animal welfare policy: Developing a comprehensive policy framework. Food Policy 2012, 37, 690-699. [CrossRef]

49. Van Soest, F.J.S.; Mourits, M.C.M.; Blanco-Penedo, I.; Duval, J.; Fall, N.; Krieger, M.; Sjöstrom, K.; Hogeveen, H. Farm-specific failure costs of production disorders in European organic dairy herds. Prev. Vet. Med. 2019, 168, 19-29. [CrossRef] [PubMed]

50. Huijps, K.; Hogeveen, H.; Lam, T.J.G.M.; Oude Lansink, A.G.J.M. Costs and efficacy of management measures to improve udder health on Dutch dairy farms. J. Dairy Sci. 2010, 93, 115-124. [CrossRef]

51. Hogeveen, H.; Huijps, K.; Lam, T.J.G.M. Economic aspects of mastitis: New developments. N. Z. Vet. J. 2011, 59, 16-23. [CrossRef] [PubMed]

52. Sjöström, K.; Sternberg-Lewerin, S.; Blanco-Penedo, I.; Duval, J.E.; Krieger, M.; Emanuelson, U.; Fall, N. Effects of a participatory approach, with systematic impact matrix analysis in herd health planning in organic dairy cattle herds. Animal 2019, 13, 358-366. [CrossRef] [PubMed]

53. Duval, J.E.; Bareille, N.; Fourichon, C.; Madouasse, A.; Vaarst, M. How can veterinarians be interesting partners for organic dairy farmers? French farmers' point of views. Prev. Vet. Med. 2017, 146, 16-26. [CrossRef]

54. Eshuis, J.; Stuiver, M. Learning in context through conflict and alignment: Farmers and scientists in search of sustainable agriculture. Agric. Hum. Values 2005, 22, 137-148. [CrossRef]

55. Hulsen, J. Cow Signals. A Practical Guide for Dairy Farm Management, UK/Ireland ed.; Roodbont: Zutphen, The Netherlands, 2012; ISBN 9789075280654.

56. Anneberg, I.; Vaarst, M.; Sandøe, P. To inspect, to motivate or to do both: A dilemma for on-farm inspection of animal welfare. In Proceedings of the 6th International Conference on the Assessment of Animal Welfare at Farm and Group Level, WAFL 2014, Clermont-Ferrand, France, 3-5 September 2014; Mounier, L., Veissier, I., Eds.; Wageningen Academic Publishers: Wageningen, The Netherlands, 2014; p. 73. 
57. McInerney, J. Animal Welfare, Economics and Policy; Farm \& Animal Health Economics Division of Defra: London, UK, 2004.

58. Bekhet, A.K.; Zauszniewski, J.A. Methodological triangulation: An approach to understanding data. Nurse Res. 2012, 20, 40-43. [CrossRef]

(c) (C) 2020 by the authors. Licensee MDPI, Basel, Switzerland. This article is an open access article distributed under the terms and conditions of the Creative Commons Attribution (CC BY) license (http://creativecommons.org/licenses/by/4.0/). 